\title{
On the Aesthetic Characteristics of Advertising
}

\author{
Yanchuan Huang \\ Yantai Nanshan University \\ Longkou, Shandong, China
}

\begin{abstract}
Advertising as a mass cultural studies in the field of a cultural phenomenon, has aesthetic value and aesthetic sense. Advertising of goods or services in the dissemination of information conveys aesthetic information. Advertising works reflected aesthetic value should be based on the product's usage information to convey, which is the basic principles and the starting point for the introduction of total advertising aesthetic skills. Advertising design artistry, is subject to the constraints of the advertising function. It demonstrated the aesthetic value of art, it should be for its information dissemination function of the service. Aesthetic value of advertising should not depart from its use value and economic value, but must be firmly rooted in material goods advertising disseminated among authenticity.
\end{abstract}

Keywords - advertising; aesthetic; form; feature

\section{INTRODUCTION}

More ads reflect the economic value or artistic value? Opinions, yet no clear conclusion. But advertising with beautiful images, a variety of artistic means (except PSAs) dissemination of economic information is an indisputable fact. So advertising has become an important means of transmitting information aesthetic. For the purpose of the campaign is not aesthetic, but the aesthetic value of your irreplaceable, is already a conclusion, and the ad manifested aesthetic value has gradually been accepted and recognized by the audience. A profound understanding of aesthetic value, aesthetic value of advertising research and advertising and aesthetic value in the traditional sense of analysis and comparison, we can more clearly advertising aesthetic artistic role and status in the campaign, and can accurately grasp the advertising aesthetic art trend and trends.

\section{APPRECIATION OF ADVERTISING ART}

\section{A. Esthetic and Commercial Sense in the Traditional Sense}

"Aesthetic" in the traditional sense is a purely "spiritual", the elegant classical arts, which is narrowly defined as the creation, appreciation of beauty. Thus aesthetic is isolated, it has its own unique way of thinking and logic, and inevitably away from politics, business, production and people's daily lives.

However, this situation with the evolution of social and economic development, with the general improvement in the quality of the public while quietly fundamental changes. That is: the "aesthetic" has been cast a strong commercial color and popular color, no longer confined to the ivory tower and art galleries interpretation of "traditional beauty", and gradually evolved into a penetration in various fields, various activities "Pan" aesthetic. Its broader extension, content has become increasingly rich and thick.

At the same time, as a trade-led rapid development of the advertising industry in just a few decades, creative standards, modes of transmission and means of information have made great progress. All these are for the further development of the aesthetic business sense to do a very good bedding.

Esthetic and commercial sense in the traditional sense of aesthetics and belong to the same field of aesthetic category, so they have the same nature. This is mainly manifested in the same, whether it is the feeling of beauty and aesthetic experience of aesthetic or commercial sense in the traditional sense on the audience derive is consistent, and this feeling and experience, can inspire their world view and Recognition of life, and thus make a positive change in thinking and behavior. This aesthetic purposes, not only, but also the business sense in the traditional sense.

Esthetic and commercial sense in the traditional sense and they have a very different nature. Aesthetic pure art no direct practical purposes, it can give a person in real life is the most difficult to obtain pure beauty of pleasure and enjoyment. The aesthetic of commercial significance, especially advertising aesthetic personality is to show merchandise, corporate or brand image, to achieve the ultimate goal of promoting the sale of products, with a strong utilitarian aesthetic color. It is much more complicated, both made profits, but also a practical purpose. Advertising aesthetic is in fact doing a unified aesthetic and practical features traditional advertising between.

It is also because advertising is done in a unified aesthetic and practical function advertising in the traditional sense between advertising that makes work more varied and broader in coverage and form of expression. It wanted to convey practical information on the evolution of the commodity form of artistic expression, to bring people in addition to purely aesthetic enjoyment, but also stimulate the potential consumer desire of the audience, and then buy the products. Which is different from the aesthetic advertising in the traditional sense of the main features.

Like other social and cultural patterns, advertising to attract and develop the aesthetics, and combined with industry characteristics, formed a rich aesthetic and cultural characteristics of their own advertising. This aesthetic form appears, it should be said that the extension and expansion of the traditional aesthetic field, but it in the traditional sense of 
aesthetics and also has a big difference, this difference is mainly reflected in total: pure artistic (in the traditional sense ) aesthetic no direct practical purpose, it gives a real-life is difficult to obtain in most purely aesthetic pleasure and enjoyment, aesthetic and commercial advertising, especially aesthetic personality is to show merchandise, corporate brand image, to achieve the ultimate goal of promoting the sale of products or services, with a strong utilitarian aesthetic color.

\section{B. Specificity and Advertising Art Aesthetic Limitations}

Advertising creative artistry, is subject to the constraints of the advertising function. It demonstrated the aesthetic value of art, the information should be conveyed to its service function, this pure art and painting art, music, dance and other aspects of photography are essentially different. Aesthetic value of advertising must not be separated from its value and economic value, it must be firmly rooted in the material goods advertising disseminated among authenticity. Otherwise, no matter what kind of aesthetic characteristics, it can only be castles in the air, mist flower, worthless.

On the other hand, the ad's use value is also severely constrained and limiting advertising aesthetic value. Because advertising is linked consumer goods and a bridge, the role of advertising is that communication and exchange. To achieve this communication and exchange, not only rely on the advertised product value and authenticity, but also rely on the ad itself artistic expression and influence, rely on them to attract or impress the audience raised their sympathy and identity. The only way to convince the audience to achieve the desired advertising goals and advertising purposes.

The famous international advertising guru William• Bernbach said, "how to say" (ad expressive) (advertising information) is more important than the "what to say." He explained: "If you do not attractive people see you the ad, then no matter what you say in your ads, you are wasting money!." In this sense, the aesthetic value of advertising on use value and sometimes plays a decisive role. Therefore, any neglect, denied advertising aesthetic value, use value tends to only consider ads are non-scientific, but also impede the forward development of advertising.

Therefore, advertising aesthetic from aesthetic in the traditional sense but its a huge difference in form, all his art to be an ad of their own value and economic value of the services. Creative reject "mediocre", but refused to be more "beautiful", any work of pure art or "aesthetic" representation on the works would be contrary to advertising aesthetic value.

\section{ADVERTISING ART AEsthetiC CHARACTERISTICS}

\section{A. Advertising Art Aesthetic "Diversity" Feature}

As technology and economic development, creative advertising techniques and production methods have been greatly improved. This also contributed to the aesthetic value of advertising showing diversity, so that ads on multiple angles and multiple levels have demonstrated the aesthetic characteristics of different styles. From the "brand-name phenomenon" to "star effect" then the advertising model, jingles, advertising film and television, and so on, drawing diverse Vying Doo-yeon.

"Famous brand" of these frequently appear in the ad, the " Celebrity", in essence, is a typical image of a particular aesthetic style. Long-term publicity through the media, many times, is widely recognized by the audience. Thereby gradually accumulated in the culture, that is, "brand name" represents the high-quality, high-grade, and the "star", "celebrity" as "opinion leaders", he has the authority. Consumers to buy "brand name" and "star" products to make your own fantasy aesthetic and aesthetic impulses can be achieved. For example, "Nike", "Rolex", "Pierre Cardin" and "Mercedes Benz" and other famous international brands has become the ideal model for people today about the lifestyle. And active in film, television, songs, sports and all areas of "celebrity", "Star" who, even more become the business enterprise the object of pursuit.

In addition, almost all of the ads Brand names are very focused art, like "Mailyard suit", "JLF wine", "Wahaha beverages" and "Double Happiness cigarettes", these brands are quite exquisite. And foreign goods brand in China in the translation is equally acclaim. For example, $P \& G$ has been translated as "Procter \& Gamble", Pepsi-cola was translated as "Pepsi", Nike sports series has been translated as "Nike", Cannon camera is translated as "Canon", Scott toilet paper is translated as "Kleenex" and other Wait. Not only embodies the use of the product, but also an irreplaceable beauty, each mood, as evidenced by the model.

As for commercial advertising in order to make use of a variety of art works and lively musical instruments, photography, poetry, movies and rap, etc., are more reflects the diversity of artistic aesthetic features of advertising.

On the one hand, they are an important component of advertising content, on the other hand, the ad also gives music, photography, poetry, movies and rap richer aesthetic style, and even spawned a new format. For example, in advertising or some beautiful songs beautiful phrases often will quickly spread to the streets to them, and some have even become classics, or the use of fixed phrases on various occasions.

Advertising as a unique cultural phenomenon of modern society, with rich and vivid aesthetic features. However, due to the inherent requirements of the advertising industry, which contain taste inevitably flow to "popular." This makes the advertising aesthetic art and life become more practical, aesthetic value and aesthetic principles lead to too superficial, not the same as with traditional aesthetic deep and lasting inspiration people. For example, some advertising in order to attract the attention of consumers, the blind pursuit of the "eyeball economy", adding some excessively vulgar, vulgar stuff in there, no beauty at all. Such a move for the sake of momentary interests, often give a negative impact on the spread of mass culture long.

Cultural consumption space, business needs and personal beautification of everyday life but we should also recognize that commercial aesthetic art, after all, belong to the public is the ultimate goal. With the further improve and perfect the advertising laws and regulations, with the gradual increase of the audience aesthetic appeal, such "pseudo-aesthetics" ads 
will lose grow soil, but also the diversity of aesthetic features of advertising will be more prominent and obvious.

\section{B. "Personalized Beauty" Aesthetic Characteristics of Advertising Art}

Due to the spread of commercial and advertising, and it embodies the aesthetic art has a distinct "personality beauty" feature that ad praises "personal charm" and taboo "Volkswagen United States." In addition to commercial works of art with painting, music, literature and other copy of the same attention to the beautiful, melody and harmony wonderful picture, pay more attention to the ad itself to the audience left a deep impression. Because the ad in order to make people aware of your customer favorite products, it is imperative to create some kind or some difference in your ad, so that your products in a number of competitors appears to have "personality" to "personal charm" to attract and impress the audience, in order to achieve the purpose of effectively communicate product information.

For example, Air China's corporate image advertising: aircraft maneuvering under the blue sky, terracotta floor suddenly square arrangement of watching the skies, the screen to launch the body of characters, "China International Airlines." The ad with China to strengthen the image of the unique terracotta warriors and stimulate the audience's vision, and through the "personal charm" to win the audience of advertising long-term memories, and ultimately remember the company and the brand image.

Advertising creative personnel in order to make boring information becomes vivid to make a brief information becomes long, often their brains to think hard, "alone on the West Wing, Wang Jin Wandering Road", trying to find product information implied in the more "personality" element, and then according to aesthetic principles, these elements back together to form a complete advertising works, it has a distinctive and unique aesthetic value and unique personality of characterization, and ultimately achieve the ultimate goal of advertising.

In short, in the form of advertising aesthetic features have diversity, but on the specific terms of advertising works, it has a "personal charm" feature, this "personal charm" irreplaceable and non-imitative in advertising aesthetic value system.

\section{CONCLUSION}

Modern mass culture category in advertising as a cultural phenomenon, it has been more than just a simple economic means, it is often also in advocating the construction of spiritual outlook, promote social values, guide and other aspects of social thought to play a certain social responsibility. Advertising aesthetic value should advance with the times, reflecting the spirit of beauty, moral beauty, artistic beauty, fashion, beauty ...... Therefore, when the creation of the ad, not only to reflect the utilitarian and practical value of advertising, but also to reflect aesthetic value to the ad.

Of course, the aesthetic value of advertising must not be separated from its value and economic value, but must be firmly rooted in product advertising material disseminated among the authenticity and practicality, otherwise, no matter what kind of aesthetic properties are not sufficient constitutes advertising aesthetic value system business sense.

In short, we should not only advertising industry as an important part of human economic life, but also as a human cultural life, spiritual life in an important and indispensable force. Any purely utilitarian or purely artistic works are nonscientific advertising only in the ad creation practical information products evolved art form, and is reflected in the spread of the process in the form of a more aesthetic value, only to values and our main task in the future advertising endeavor.

\section{REFERENCES}

[1] jin xiexie, Shang Xiaoli. Aesthetic art of commercials [J]. Chinese culture, 1997, (3)

[2] ]xia qianfeng. On the aesthetic and cultural value of advertising and advertising [J]. News University, spring 2000.

[3] qian chaoyang. Advertising Aesthetics [J]. Shanghai University, 2001.12. Vol. 8 (6)

[4] yin lufa 、 xu shuan. Ancient Chinese Culture [M] Beijing: Peking University Press, 1989.35-192.

[5] zhang jinhai. World classic advertising case analysis [M]. Wuhan: Wuhan University Press, 2000.12-66. 